\title{
A escola-medusa: o olhar do outro e a educação em Jean- Paul Sartre
}

Danilo Arnaldo Briskievicz*

Instituto Federal de Minas Gerais

Resumo Investigamos a ontologia do olhar proposta por Jean-Paul Sartre em seu livro O ser e o nada: Ensaio de Ontologia Fenomenológica, publicado em 1943, a fim de problematizar as relações intersubjetivas na formação escolar em particular, e na educação, em geral. Aproximando-nos do texto sartriano, demonstramos como a forma de olhar e de ser olhado é estruturante do Para-si e de sua dimensão do ser-Para-outro. A partir da controvertida figura metafórica da escola-medusa, remetendo-nos ao mito grego antigo de Medusa que petrificava quem a olhasse diretamente, estabelecemos um diálogo entre a ontologia sartriana e a pedagogia. A partir da análise rigorosa da categoria do ser-Para-outro (être-Pour-autrui) destacamos as relações possíveis entre os estudantes e os professores no ambiente escolar em que se dá a relação intersubjetiva, ou dito de outra forma, a relação pedagógica entreolhares. A metodologia utilizada é uma pesquisa bibliográfica de alguns textos sartrianos e de alguns de seus comentadores. O resultado pretendido é uma colaboração em torno da ontologia do olhar, no interior das discussões propostas pela Filosofia da Educação.

PALAVRAS-ChAVE: Ontologia do olhar; Ser-Para-outro; Intersubjetividade. 
The medusa-school: the look of the other and education in Jean-Paul Sartre

Abstract We investigated the ontology of look proposed by Jean-Paul Sartre in his book Being and Nothingness: An Essay on Phenomenological Ontology, published in 1943, in order to problematize intersubjective relations in particular school formation, and education in general. Approaching the Sartrian text, we demonstrate how the way of looking and being looked at is structuring of the Self and its dimension of Being-to-other. From the controversial figure of the school-medusa, referring to the ancient Greek myth of Medusa that petrified who looked directly at it, we established a dialogue between Sartre's ontology and pedagogy. From the rigorous analysis of the category of being-to-other (être-Pour-autrui) we highlight the possible relations between students and teachers in the school environment in which the intersubjective relationship occurs, or put another way, the pedagogical relationship interchangeable. The methodology used is a bibliographical search of some Sartrian texts and some of their commentators. The desired result is a collaboration around the ontology of the look within the discussions proposed by the Philosophy of Education.

KEYWORDS: Ontology of the Look; Being-for-others; Intersubjectivity.

\section{O problema: que é o ser revelado pelos olhares na escola?}

Há homens que morrem sem haver suspeitado, sequer salvo durante breves e aterradoras iluminações, o que seja o outro.

\section{J.-P. Sartre}

O filósofo francês Jean-Paul Sartre (1905-1980) publicou o livro O ser e o nada: ensaio de ontologia fenomenológica, em 1943. "O olhar" é a quarta unidade do capítulo primeiro da terceira parte intitulada "O para-outro". Trata-se de uma investigação acerca da possibilidade de interação entre os seres constituídos ontologicamente no mundo convivencial, ou seja, a relação conhecida no universo escolar como a socialização, a relação entre o eu e o outro. A pergunta sobre o olhar, o entreolhares, se situa no âmago da conceituação do ser-Para-outro dado aos outros enquanto corpo aparecido no mundo. Determinar a existência ontológica do Outro pelo olhar é um caminho possível para afirmar que estamos no mundo juntos, engajados na existência. Essa existência é perpassada por instituições sociais, sendo a escola a mais perceptível, a mais visível para a análise do olhar. Nesse sentido, a escola tem uma dimensão panóptica, ou seja, a sua estruturação pelo olhar - ver e ser visto -, nos remete à consciência de uma constante e permanente visibilidade pelos outros, o que de certa maneira, asseguraria o funcionamento de um poder autoritário. Jeremy Bentham et ali (2008, p. 75) comenta - num contexto bastante diferente de Sartre, mas que nos auxilia em nossa problematização do olhar -, que o princípio de inspeção que fundamenta as prisões, hospícios e hospitais está presente na educação, na escola. Dessa forma, na escola "toda 
brincadeira, toda conversa, em suma, toda distração de qualquer tipo, está efetivamente descartada pela situação central e protegida do mestre" que acaba por inspecionar o que fazem os alunos "secundado pelas partições de telas - tão discretas quanto se queira - entre os estudantes." Dessa forma, parece que o olhar do mestre depois de introjetado se torna eficaz no controle da ação dos alunos. São os entreolhares que podem acontecer de fato ou de maneira imaginada.

A educação é feita por olhares múltiplos, diversos, plurais. As mediações entre professores e alunos através das pedagogias podem se dar das mais diferentes formas, de acordo com as condições sociais, políticas, econômicas e existenciais. Nesse sentido, há vários olhares possíveis para a escola, o espaço determinado na modernidade para o processo de educação dos recém-chegados ao mundo pelo nascimento (ARENDT, 1992, p. 221-247). A escola enquanto espaço de educação é composta por entreolhares: os mais diversos sujeitos, as mais diversas motivações agem para a constituição desse espaço de convivência social entre crianças e jovens e adultos (JOSGRILBERG, 2015, p. 9).

A multifacetada realidade escolar e educacional impõe um questionamento acerca da possibilidade ontológica da educação. As pedagogias podem orientar no sentido de que haja maior ou menor centralidade do ensino nas crianças e jovens ou no professor. Podem indicar as formas de melhorar a atuação em sala de aula para que o conhecimento aconteça de forma satisfatória. Contudo, para que haja sujeito que aprende e outro que ensina, preciso é se perguntar: que seres são professores e alunos? Que é o ser revelado no espaço escolar pelo olhar? O que somos é um problema ontológico que nos coloca no movimento da busca deste ser e de suas possíveis manifestações. Uma pista de quem somos se revela pelo olhar. Por ele, na escola, quem somos se revela como Para-outro. Cada professor e cada aluno é um ser-Para-si sendo ser-Para-outro: se olham, interagem, dialogam, mediatizam seu ser, revelando-o no ambiente escolar. Nesse ambiente de entreolhares captamos e somos captados pelo olhar do Outro. Importante ressaltar que o conceito de Outro refere-se à estruturação ontológica do Ser, enquanto o termo outro pode ser qualquer coisa: na educação estamos diante do olhar do Outro, aquele que impõe sua presença e exige uma resposta, não de um outro qualquer apenas, que exige apenas uma relação qualquer de apreensão pelos sentidos. Por isso, o olhar do Outro nunca é vago, vazio ou desprovido de sentido. Sempre que o olhar coloca um ser diante do Outro podemos petrificá-lo ou libertá-lo, sendo que nesse jogo há muitas gradações de como vemos e como somos vistos, mas jamais ficaremos indiferentes. Nesse sentido, a escola-medusa é uma metáfora para dizer da escola enquanto lugar de entreolhares.

Portanto, Jean-Paul Sartre investiga o olhar como revelação do ser-Para-si como ser-Para-outro. O olhar é o ato de revelação do ser-Para-outro e é o fundamento do conhecimento. Por isso, para Chauí (1998, p. 35) "ver é olhar para tomar conhecimento e para ter conhecimento" e "esse laço entre ver e conhecer, de um olhar que se tornou cognoscente e não apenas espectador desatento, é o que o verbo grego eidô exprime;" eidô significa "ver, observar, examinar, fazer ver, instruir, instruir-se, informar, informar-se, conhecer, saber - e, no latim, da mesma raiz, vídeo - ver, olhar, perceber - e viso - visar, ir olhar, ir ver, examinar, observar." Por isso, "quem olha, olha de algum 
lugar.” É assim que a ontologia fenomenológica sartriana nos auxiliará na investigação acerca do encontro entre professores, crianças e jovens na escola, para que seja possível o que designamos por educação.

Nossa investigação centra-se em uma pesquisa bibliográfica da obra sartriana $O$ ser e o nada, no capítulo sobre "O olhar" e de alguns de seus comentadores e de pensadores da educação. $O$ resultado esperado é a conceituação do olhar na ontologia sartriana e algumas de suas repercussões na educação. Nosso artigo pretende ser uma contribuição para a discussão da ontologia na Filosofia da Educação enquanto disciplina preocupada em repensar as possibilidades do ato de educar em sua radicalidade.

\section{A escola-medusa e seus monstros}

O que é um olhar? O olhar não se encontra nos olhos. Observação de Sartre: "O olhar do Outro esconde seus olhos". Observação de Cecília Meireles: "O sentido está guardado no rosto com que te miro". Eu não te miro com os meus olhos. Eu te miro com o meu rosto. Os olhos são peças anatômicas assustadoras em si mesmas. Olhos não têm sentido. Eles nada dizem. Mas o rosto com que te miro guarda um segredo. Não miro com os olhos. Miro com o rosto. É o rosto que desvenda o mistério do olhar. $\mathrm{O}$ rosto da mãe revela à criança o segredo do seu olhar. Isso é verdade até para os animais: o olhar de um cão...

Rubem Alves

O eu, para Sartre, é o ser-Para-si (fr.: être-Pour-soi). Tudo o que está fora da consciência, é o ser-Em-si (fr.: être-En-soi). O Para-si convive com os outros eus, com outros Para-sis a partir da dimensão do ser-Para-outro (fr.: être-Pour-autrui). A existência nunca se dá sozinha, ela é o exercício da liberdade entre os outros, é uma condição: "Sartre reflete, assim, que a criança se faz mediante um movimento em que a universalidade é vivida na particularidade, numa complexidade dialética" em que a família e a escola são realidades vividas e negadas pela criança, "ou seja, na exata medida em que a criança é produto dele, submetida, ela também dele é produtora, transcende, singulariza o que está posto" (PRETTO, 2013, p. 624). Toda a troca com o mundo para a constituição de nossa condição humana se dá entreolhares: "as situações históricas variam: o homem pode nascer escravo em uma sociedade pagã ou senhor feudal ou proletário. O que não varia é a necessidade, para ele, de estar no mundo, trabalhar, conviver com outras pessoas e ser, no mundo, um mortal" (SARTRE, 2014, p. 35). O olhar alheio é na maioria das vezes o ponto convergente da aceitação ou negação do eu pelos outros. Essa condição do Para-si é criadora, o ponto de partida para que existam coisas no mundo. A condição humana se dá com a constituição do eu e do outro, no surgimento do para si como um ser-Em-si-no-meio-do-mundo, como coisa pensante e pensada. Por isso, a condição humana é um jogo entre Para-sis que são para-Outros e que, por isso, pode ser a Medusa alheia. Petrificamos os outros com nossa presença e "esta petrificação em Em-si pelo olhar do Outro é o sentido profundo do mito da Medusa”(SARTRE, 2015, p. 531).

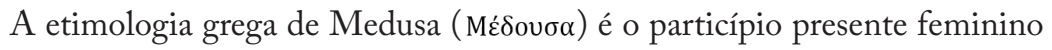
do verbo $\mu \varepsilon \delta \varepsilon \varepsilon v$ (médein), de onde vem o sentido alargado de quem comanda, quem rei- 
na, derivando as palavras medida, moderação, meditação; em sentido amplo, médein designa o assumir com autoridade as medidas apropriadas (BRANDÃO,2008). Olhar de Medusa é um olhar de comando: ver o Outro é ver-se ao mesmo tempo, é colocarse diante do Outro e estar no mundo em uma condição particular. A escola-medusa pode ser aquela que ensina por autoridade dos adultos ou que intimida pelo medo; ela pode ser bela ou apavorante. É nesse sentido que para os antigos habitantes da Grécia, Medusa era uma mulher com serpentes na cabeça, possuía presas de bronze, dentes de javali e pele de escamas de ouro. Medusa, Euriále e Esteno eram górgonas, nascidas belas e de cabelos invejáveis, contudo, desregradas e sem escrúpulos. A deusa Atena por inveja da beleza das irmãs, uma beleza sem sabedoria, deformou-lhes a aparência e as degredou para a Ciméria, o país da noite eterna. Das três górgonas, apenas Medusa era mortal. Quem olhasse diretamente para seus olhos flamejantes e penetrantes seria transformado em estátua de pedra (HESÍODE, 1872, p. 12). Medusa era mortal: a escola também é uma obra humana, sujeita a falhas e sucessos. A mortalidade da escola-medusa significa que ela está inserida numa história surpreendentemente mutável e precisa se recriar para continuar cativando crianças e jovens em seus entreolhares.

Para Sartre e, de maneira geral, para os contemporâneos, o mito da Medusa retrata a situação da convivência social em que nos deparamos com o olhar do Outro o tempo todo, o Outro representado em sua diferença absoluta e amedrontadora (VERNANT, 1991; BRUNEL, 1996). O significado retratado até aqui nos remete à escola como espaço de petrificações cotidianas que acontecem pelo olhar. $\mathrm{O}$ encontro entre professores e alunos amedronta ambos, permite que entreolhares a educação aconteça. A escola é um palco do mundo, em que a situação de petrificação pode se aprofundar ou pode criar a possibilidade de libertação do senso comum trazidos pelas crianças e jovens para o interior da instituição. Compreender o que é olhar e como ele constitui a possibilidade da educação e da escola é que vamos analisar em seguida.

\section{O mundo entreolhares: a escola onde vejo e sou visto}

A realidade humana é vivida temporalmente no Para-si. É somente no plano do cogito que podemos pensar o Para-si uma vez que ele "não se mistura nem com o Ser-em-si das coisas, nem com os outros Para-si", mantendo sua individualidade por ser "pura espontaneidade, consciência daquilo que é e em direção ao seu próprio ser" (FURLAN, 2016, p. 12). Mas o Para-si é afetado pelo Outro. Isso quer dizer que dentro do Para-si, há uma dimensão do Para-outro. Para Sartre, nós constituímos o Outro "aos poucos como objeto concreto" já que "não é o outro o instrumento que serve para prever um acontecimento de minha experiência, mas os acontecimentos de minha experiência é que servem para constituir o outro enquanto outro," uma vez que ele é "sistema de representações fora de alcance, como objeto concreto e cognoscível" (SARTRE, 2015, p. 297). A consciência de estar no mundo do Para-si é ampliada pela presença dos outros e, por isso, para que possamos estar plenos no mundo, estamos conectados ontologicamente com os outros, pelo cogito. Somos afetados pelo Outro pois em nossa constituição de Para-si somos também Para-outros derivando daí a possibilidade da alienação, de que o Outro, o alheio interfira na nossa forma de pensar e agir no mundo. Isso implica dizer que, no plano racional, do cogito, vivemos 
interconectados com os outros, afetados por eles, amalgamados a outras realidades, vivendo dentro de si a dimensão da alteridade. É por isso que a "existência do Outro é tão certa como a do mundo, compreendendo no mundo minha existência psicofísica" (SARTRE, 2015, p. 305). Nesse sentido, somos conectados pela experiência e para além dela. O Outro media o mundo com cada Para-si. Vivemos numa "pluralidade das consciências" (SARTRE, 2015, p. 306) em que "eu sou tal como apareço ao Outro" em que "o valor do reconhecimento de mim pelo Outro depende do valor do reconhecimento do Outro por mim" e assim, arrisco viver com os outros, uma vez que "arriscar a vida, com efeito, é revelar-se" (SARTRE, 2015, p. 307). A liberdade do Para-si permite que tenha relações com o Outro, de ser para ser, uma relação umbilical pelo cogito: se a existência do Outro não é uma conjectura inútil, pura ficção, apenas uma idealização, é porque existe algo como um cogito que lhe diz respeito. A revelação do cogito no mundo é "o projeto de ser" que "é aberto, aponta para o que ainda não é, posto que aquilo que caracteriza a especificidade do humano é ser desejo, nada, implicado com aquilo que falta, com o futuro sendo este desejo, desejo de ser aberto a diferentes possibilidades" (PRETTO, 2013, p. 625). Assim, o Outro não é apenas um objeto inerte diante do Para-si, ele é outro Em-si-para-Outro, com sua realidade humana e com o qual construo minha existência como projeto, como projeção do meu Para-si. Nesse processo de alterização, própria do processo de socialização, há o encontro entre o conhecimento de mundo dos professores e o senso comum dos alunos. A responsabilidade em agir com o Outro me indica que "o que eu me faço ser é um modo de ser. Tanto é verdade que sou responsável pelo meu ser-Para-outro, na medida em que o realizo livremente na autenticidade ou na inautenticidade" (SARTRE, 2015, p. 318). É na coexistência entre a diversidade de Para-sis "nós encontramos o Outro" (SARTRE, 2015, p. 323), abrindo-nos para a convivência no mundo. Nesse sentido, o cogito individualizado, unicizado, diferenciado, próprio, exclusivo se aperfeiçoa em sua condição existencial diante do Outro e é somente por causa dele que recebemos a presença do Outro, através dos olhares.

O olhar do outro nos acompanha desde o nascimento. Somos vistos e vemos. Somos aparecidos enquanto ser uns para os outros. Reagimos à visão que o outro tem do meu corpo no mundo. É Chauí (1998, p. 58) que demonstra que o corpo, meu corpo, o corpo do outro,

Não é coisa. Não é feixe de nervos, músculos e sangue. Não é central de informação nem receptáculo de estímulos. Não é fisiologia de processos 'em terceira pessoa', descritos segundo princípios mecânicos e funcionais que o fazem simples exterioridade de partes extra partes. Não é recipiente passivo da atividade anímica, espiritual ou intelectual. Não é fato inspecionado pelo entendimento. Não é suporte empírico de formas a priori, nem coisa anatômica. Não é ideia clara e distinta, nem o 'isto' abstrato da sensação a ser desenvolvido especulativamente pelo espírito. O corpo é um 'sensível exemplar'.

Na família, na escola, no espaço público, somos vistos e vemos os outros. Por isso, para o cogito, o Outro aparece inicialmente como olhar pois enquanto não há nenhum outro Para-si diante de nossos olhos, tendemos a organizar as coisas ao nosso redor tendo a nós mesmo por centro, e quando surge o Outro advem a perturbação e somos atraídos pelo olhar ao Outro e passamos a ser um objeto do mundo. Evidente- 
mente, o movimento do cogito é duplo: de si para o Outro, consituindo-se na presença real ou imaginada do Outro.

Mas o que é, de fato, o olhar? O que ele revela do Para-si? Num primeiro momento, que todo Para-si visto e que vê está na presença dos outros, através do olhar que nos constitui como "ser-em-par-com-outro" (SARTRE, 2015, p. 327). A aparição diante dos outros realiza o reconhecimento do Para-si no mundo e, ao mesmo tempo, a "desintegração deste universo", o que ocorre pelo surgimento "de um homem no meu universo". Por isso, o "Outro é, antes de tudo, a fuga permanente das coisas ruma a um termo que capto ao mesmo tempo como objeto a certa distância de mim e que me escapa na medida em que estende à sua volta suas próprias distâncias" (SARTRE, 2015, p. 329). Num segundo momento, o Para-si é afetado pelo olhar alheio por ter em sua constituição ontológica a dimensão do para-Outro. É por isso que ao ser visto pelo olhar do outro revela "um deslizamento fixo de todo o universo, a uma descentralização do mundo que solapa por baixo a centralização que simultaneamente efetuo" (SARTRE, 2015, p. 330). O aparecimento do olhar do outro me desloca para outra percepção de mim mesmo no mundo. O olhar do outro nunca me é indiferente uma vez que "não se limita a objetivar-me: ele descobre-me também, conhecendo-me mais e melhor do que eu conseguiria por mim próprio" (MORAVIA, 1985, p. 55-56). Portanto, os dois momentos relatados - a aparição e o afetamento pelo olhar do outro, permitem fazer duas observações em relação à escola. A primeira é que o encontro entre professores e alunos é um deslocamento de um e de outro para a efetiva constituição de um espaço "ser-em-par-com-outro"; a segunda é que diante do outro nunca estaremos operando na vacuidade do pensamento, ou seja, o mais indiferente aluno em classe estará sendo afetado pelo outro-professor, outro-colega, outro-pai, outromãe, em seu mundo. Com isso, rompe-se a ideia de que haja uma total indiferença entre Para-sis: a apatia é uma forma de reagir ao outro que entrou no meu universo de percepção, e se este é negado categoricamente temos a má-fé. Nesse sentido, negar o outro diante de mim "é uma mentira, pois dissimula a total liberdade do engajamento" (SARTRE, 2014, p. 39) através do olhar alheio. A má-fé é uma desculpa para evitar o envolvimento com o outro que está diante de mim pelo olhar.

A escola é um lugar de visibilidade em que somos vistos pelo outro. Por isso, "o 'ser-visto-pelo-outro' é a verdade do 'ver-o-outro"' (SARTRE, 2015, p. 332). O espaço escolar é de endereçamento de olhares, em que o Para-si mirando outro Para-si se constituem a si mesmos. Nessa troca de olhares, "todo olhar endereçado a mim se manifesta em conexão com a aparição de uma forma sensível em nosso campo perceptivo, mas, ao contrário do que se possa crer, não está vinculado a qualquer forma determinada" (SARTRE, 2015, p. 332). De fato, uma coisa é olhar quem pede para ser visto, outra coisa é sentir-se tocado na interioridade pelo olhar do outro. São coisas diferentes: "o olhar é, antes de tudo, um intermediário que remete de mim a mim mesmo” (SARTRE, 2015, p. 333-334). Ser visto é notar-se no mundo pelo olhar do outro. O Outro obriga o Para-si a centrar-se em sua posição de observador de si mesmo, fazendo com que ele se veja por que alguém o vê, como exigência do disciplinamento dos corpos exigido pelo panóptico. Por isso, a visibilidade escolar é um fenômeno ontológico corriqueiro em que centramos e somos centrados pelo Outro. Nesse sentido, a visibilidade através do "olhar do Outro me faz ser para-além de meu ser nesse mundo, 
no meio de um mundo que é, ao mesmo tempo este mundo e Para-além deste mundo" (SARTRE, 2015, p. 337). De fato, "toda a minha relação com o outro está condicionada pelo poder ser visto pelo outro" (BORNHEIM, 2005, p. 86-87).

A vergonha, sentimento próprio das instituições sociais, inclusive a escola, é um exemplo de como se dá a relação entre para-Outros através do olhar. Sentir vergonha é estar diante do olhar do outro numa situação de percepção de si mesmo. A vergonha revela quem somos diante do outro, imediatamente e por isto "basta que o Outro me olhe para que eu seja o que sou" pois imediatamente, "capto o olhar do outro no próprio cerne de meu ato, como solidificação e alienação de minhas possibilidades" (SARTRE, 2015, p. 338). A vergonha é um cair em si diante pelo olhar do Outro que "vem me buscar no cerne de minha situação" (SARTRE, 2015, p. 339). A vergonha na escola é um dos fenômenos mais corriqueiros pois a instituição é um espaço conflituoso para construção da personalidade de crianças e jovens (TAILLE et al, 1992). Nesse sentido, a vergonha remete à ideia de que "o Outro é a morte oculta de minhas possibilidades, na medida em que vivo esta morte oculta no meio do mundo" (SARTRE, 2015, p. 340). A vergonha permite absorver que o Para-si se constitui na dimensão do para-Outro uma vez que causa um mal-estar diante do outro. Por causa da vergonha do outro, vivida dentro do Para-si, corro o risco de ser revelado diante do olhar alheio e "através dele estou perpetuamente em perigo em um mundo que é esse mundo" (SARTRE, 2015, p. 353). A experiência de vergonha fornece, de acordo com Sartre, uma ilustração do que nossos relacionamentos com os outros podem ser, em determinadas circunstâncias. A vergonha é vergonha de si mesmo, mas para outra consciência. Nesse sentido, "a vergonha em sua estrutura primeira é vergonha de alguém. O outro não só me revelou aquilo que eu era. Ele me constituiu um tipo de ser novo que deve suportar qualificações novas" (GILES, 1975, p. 342). Sentir vergonha é, portanto, "estar comprometido com a crença de que não se está sozinho, pois faz parte do próprio conceito a existência de outros como uma estrutura de nossa própria consciência" e por isso "a estrutura da vergonha é tal que não se poderia supor capaz de envergonhar-se alguém que não tivesse o conceito de outras pessoas: o sentimento só pode surgir com referência a outras pessoas" (DANTO, 1975, p. 86).

O olhar do Outro é um espacializador e um temporalizador. O tempo de apreensão do olhar do outro cria no Para-si a dimensão de deslocamento do registro. Um registro que até então passava despercebido, passa a ter um registro espacial e temporal, que poderá ser lembrado posteriormente. Cria-se, por isso, uma simultaneidade em que o Para-si se conecta com outro Para-si, dito de outra maneira, o encontro de Para-sis só é possível por que existe a dimensão do para-Outro em cada um deles: a "simultaneidade presume conexão temporal de dois existentes não vinculados por qualquer outra relação" uma vez que "o olhar do outro, na medida em que o apreendo, vem atribuir a meu tempo uma dimensão nova” (SARTRE, 2015, p. 343). O instante educativo é a formalização do entreolhares em que o Para-si do professor intenciona encontrar respaldo no Para-si de cada aluno. Esse instante de simultaneidade (MÉSZÁROS, 2012, p. 208) é o ponto central das pedagogias, o momento em que a formação principia. $\mathrm{O}$ estar frente a frente com os alunos pressupõe um entreolhares simultâneo. Nesse sentido, para Sartre, o sujeito é, "por definição, resultante de suas relações que se dão num espaço e num tempo e mediante um fluxo de consciências pelo qual 
este sujeito" acaba por perceber, imaginar, refletir, emocionar-se, pensar e sedimentar sentimentos, sua ação no mundo, em que ele organiza-se em "coletivos com diferentes características e constitui, a partir de um movimento de subjetivação e objetivação, a coloração específica ou a singularidade de seu projeto e desejo de ser no mundo" (PRETTO, 2013, p. 628). O instante de simultaneidade revela que o olhar do outro é inderivável, obriga o Para-si a reconhecer-se situado no mundo, mesmo que o mundo ao redor. De fato, "a presença do Outro em seu olhar-olhador não poderia contribuir para reforçar o mundo; ao contrário, ela o desmundaniza, pois faz justamente com que o mundo me escape" e por isso, "a presença a mim do outro-olhar [...] simplesmente é, e não posso derivá-la de mim" (SARTRE, 2015, p. 349). Cabe ao professor criar o instante da simultaneidade para que a educação se efetive entreolhares.

Portanto, a cada troca de olhares em sala de aula há um desejo de que o encontro seja de longa duração na vida dos alunos. A educação intenciona ser de longo prazo na vida das crianças e jovens. A escola pretende marcar a vida dos alunos beneficiando-os a longo prazo. Isso é possível pela qualidade dos olhares trocados no processo ensino-aprendizagem, na criação do instante da simultaneidade que, de acordo com sua intensidade, pode ser prolongado, uma vez que "o Outro está presente a mim onde quer que seja, como aquilo pelo qual eu me torno objeto" (SARTRE, 2015, p. 358). A duração da educação na vida de crianças e jovens depende, pois, dos olhares trocados no interior da escola. É por conta desses olhares que a educação se efetivou. Assim, "cada olhar nos faz experimentar concretamente - e na certeza indubitável do cogito - que existimos para todos os homens vivos, ou seja, que há consciência(s) para quem existo" e, por isso, "o olhar nos colocou no encalço de nosso ser-Para-outro e nos revelou a existência indubitável deste Outro para o qual somos” (SARTRE, 2015, p. 360-361).

A escola-medusa se constitui numa figura retórica importante para questionar a educação em relação ao seu papel social. Ser apavorante ou libertadora, ser amedrontadora ou prazerosa depende dos processos desenvolvidos a partir da consideração de que estamos diante de Para-sis que se engajam no mundo a partir da dimensão do Para-outro. Tornar a escola um espaço de entreolhares significativos seja, talvez, a maior obrigação da escola nos dias atuais.

\section{Conclusões}

O seu olhar, professor, produz alterações no corpo da criança. $\mathrm{O}$ olhar de um professor tem o poder de fazer a inteligência de uma criança florescer ou murchar. Ela continua lá, mas se recusa a sair para a ventura de aprender. A criança de olhar amedrontado e vazio, de olhar distraído e perdido. Ela não aprende. Os psicólogos se apressam em diagnosticar alguma perturbação cognitiva. Pode até ser. Mas uma outra hipótese tem que ser levantada: que a inteligência dessa criança que parece incapaz de apreender tenha sido enfeitiçada pelo olhar do professor.

Por isso lhe digo, professor: cuide de seus olhos...

Rubem Alves 
A figura da escola-medusa é uma provocação pedagógica. De fato, questionar-se a respeito dos entreolhares escolares nos remete à missão precípua da pedagogia: apresentar às crianças e jovens o mundo dos adultos, inseri-los no mundo que lhes pertence e que será herdado por cada um deles para lhes dar continuidade (ARENDT, 1992, p. 221-247).

Nesse sentido, em primeiro lugar, a ontologia do olhar sartriana nos permitiu alargar o conceito de intersubjetividade que acontece por uma estrutura interna do Para-si que é o ser-Para-outro. O encontro pela educação de sujeitos tão diversos é possível pois somos ontologicamente constituídos para nos revelar uns aos outros no espaço de convivência. Em segundo lugar, a noção de instante de simultaneidade nos permitiu inferir que o olhar é o fundamento do pedagógico e do didático. Tratase de criar um espaço em que entreolhares nos revelamos, interagimos e construímos conhecimento. Este instante é altamente provocador pois é a partir dele que se pode iniciar a instrução escolar. Por fim, a ontologia do olhar nos mostrou que a existência é condicionada pelo outro, e quanto mais se conhece o outro, mais se conhece a si mesmo, num constante processo de construção da alteridade. É por isso que a escola não é um lugar destituído de conflitos e tensões: a intersubjetividade através do entreolhares é construída entre medos e sonhos, entre pavores e alegrias, entre espantos e lucidez. A sala de aula é um espaço de olhares que dizem, questionam, revelam, estimulam, provocam o outro a ser ele mesmo em exercício de libertação e liberdade. Assim,

É preciso olhar detalhadamente. Olhar de percepção, brincalhão, curioso, mas nossos olhos não foram educados para isto, ao contrário, foram vendados. Neles foram depositadas muitas informações que foram se cristalizando e provocando cegueira. Focamos como que anestesiados dos olhos. Não seria então escola uma possibilidade de exercitar o nosso olhar? De tirar as vendas? Não poderia a interação constituir em um espaço para apurarmos nosso olhar? Aprendemos a olhar olhando e refletindo sobre o próprio olhar (CARNEIRO, 2005, p. 35).

Portanto, a partir de nossa intenção inicial, acreditamos ter mostrado sem a pretensão de esgotamento do tema, o que é a ontologia do olhar para Jean-Paul Sartre e suas possibilidades para a educação, avançando nesse ponto no interior da Filosofia da Educação.

\section{Referências}

ALVES, Rubem. Gaiolas ou Asas: a arte do voo ou a busca da alegria de aprender. 1.ed. Porto: Edições Asa, 2004.127p.

ARENDT, Hannah. A crise da educação. In: ARENDT, Hannah. Entre o passado e o futuro. 3.ed. São Paulo: Perspectiva, 1992, p. 221-247.

BENTHAM, Jeremy et ali. O panóptico. 2.ed. Belo Horizonte: Autêntica, 2008, 201p.

BORNHEIM, Gerd. Sartre: Metafísica e Existencialismo. 3.ed. São Paulo: Perspectiva, 2005. 315 p.

BRANDÃO, Junito de Souza. Dicionário mítico-etimológico. Volume 1. 15.ed. Petrópolis: Vozes, 2008. 701p. 
BRUNEL, Pierre. (ed.). Companion to Literary Myths, Heroes and Archetypes. 1.ed. London; New York: Routledge, 1996.1223p.

CARNEIRO, Maria Cristina C. de A. Cidadania: a educação do olhar. Revista de Educação do Cogeime, São Paulo, n.27, p.33-41, dez. 2005.

CHAUÍ, Marilena. Janelas da alma, espelhos do mundo. In: NOVAES, Adauto (Org). O olhar. São Paulo: Cia das Letras, 1998, p. 31-61.

DANTO, Aarthur C. As ideias de Sartre. 1.ed. São Paulo: Cultrix, 1975.127p.

FURLAN, Reinaldo. A importância da discussão sobre a noção de sujeito: Foucault, Sartre, Merleau-Ponty. Educação e pesquisa [online], São Paulo, In press, p. 1-19, set. 2016.

GILES, Thomas Ranson. História do Existencialismo e da Fenomenologia. Volume 2. 1.ed. São Paulo: Edusp, 1975.367p.

HESÍODE. La Théogonie d'Hésiode. 1.ed. Paris: Typographie Georges Chamerot, 1872.32p. JOSGRILBERG, Rui. Fenomenologia e Educação. Notandum, Porto, n. 38, p.5-14, maio-ago. 2015.

MÉSZÁROS, István. A obra de Sartre: busca da liberdade e desafio da história. 1.ed. São Paulo: Boitempo Editorial, 2012.330p.

MORAVIA, Sérgio. Sartre. 1.ed. Lisboa: Ed. 70, 1985.183p.

PRETTO, Zuleica. A infância como acontecimento singular na complexidade dialética da história. Psicologia \& Sociedade, Belo Horizonte, n. 25, p. 623-630, 2013.

SARTRE, Jean-Paul. O existencialismo é um humanismo. 4.ed. Petrópolis: Vozes, 2014. 62p.

SARTRE, Jean-Paul. O ser e o nada. Ensaio de Ontologia Fenomenológica. 24.ed. Petrópolis: Vozes, 2015. 782p.

TAILLE, YVES de la et al. Construção da fronteira da intimidade: a humilhação e a vergonha na educação moral. Cadernos de Pesquisas, São Paulo, n. 82, p.43-55, ago. 1992.

VERNANT, Jean-Pierre. La mort dans les yeux. [Question à Jean-Pierre Vernant]. Mètis: Revue d'Anthropologie des mondes grecs anciens, Paris, n.1-2, p. 283-299, 1991.

* Professor titular de Filosofia e Sociologia do Instituto Federal de Educação, Ciência e Tecnologia de Minas Gerais, Santa Luzia, Minas Gerais, Brasil.

\section{Correspondência}

Danilo Arnaldo Briskievicz - Instituto Federal Minas Gerais, Instituto Federal de Minas Gerais - Santa Luzia. Rua Érico Veríssimo, 317. Londrina. CEP: 30850470. Santa Luzia, Minas Gerais, Brasil.

E-mail: doserro@hotmail.com

Recebido em 30 de maio de 2017

Aprovado em 20 de março de 2018 
